\title{
Cost effectiveness of cardiovascular disease prevention strategies: a perspective on EU food based dietary guidelines
}

\author{
Eric Brunner ${ }^{1, *}$, David Cohen ${ }^{2}$ and Lynn Toon ${ }^{1}$ \\ 'International Centre for Health and Society, Department of Epidemiology and Public Health, University College \\ London Medical School, 1-19 Torrington Place, London WC1E 6BT, UK: ${ }^{2}$ Business School, University of Glamorgan, \\ Pontypridd, CF37 1DL, UK
}

\begin{abstract}
For policymakers considering strategy options for the prevention of cardiovascular disease (CVD) the distinction between effectiveness and cost effectiveness is critical. When cost limitations apply, an evaluation of cost effectiveness is essential if a rational decision is to be made. Policy changes and resource reallocation have opportunity costs, and therefore it is necessary to compare the cost of health gains achievable by means of different policies. Here the broad question is: How cost effective are diet change strategies compared to other measures aimed at reducing cardiovascular disease in EU member states?

An overview of published studies of cost-effectiveness in the primary and secondary prevention of cardiovascular disease was conducted. Few comprehensive studies were available.

Estimated costs per life year gained were as follows: population-based healthy eating $£ 14-560$; smoking cessation £300-790; nurse screening and life style advice £.900 (minimum); simvastatin (HMGCoA reductase inhibitor) £6200-11 300. Cost effectiveness is dependent on the underlying level of CVD risk in the target population, and the duration of the achieved alterations in behaviours and risk factors.

The limited evidence from these studies tends to support the view that health protection strategies which promote healthy eating are likely to be more costeffective than strategies involving modern cholesterol-lowering drugs, screening and advice in primary care, and are comparable to or less expensive per year of life saved than anti-smoking strategies. Given the considerable diversity in food habits, health care and public health systems among current and prospective EU member states, careful appraisal of the policy options within each member state is desirable to ensure that health gain is maximised. EU wide food based dietary guidelines are potentially the basis of large health gains in Europe, and cost-effectiveness studies tend to support their adoption.
\end{abstract}

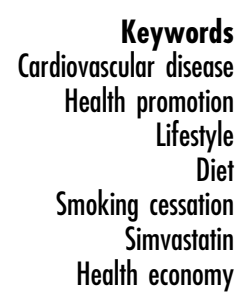

\section{Introduction}

For policymakers considering strategy options, the distinction between effectiveness and cost effectiveness is critical. In the rare case that a policy objective is to be pursued with no limitation on spending, then effectiveness (the beneficial effect of a strategy in practice rather than under ideal conditions) is the primary consideration $^{1}$. When cost limitations apply, an evaluation of cost effectiveness is essential if a rational decision is to be made.

Here the broad question is: How cost effective are diet change strategies compared to other measures aimed at reducing cardiovascular disease (CVD) in EU member states? The potential health gains from implementing policies based on EU food based dietary guidelines are substantial, given what we know about the nutritional basis of degenerative disease and current and future dietary intakes in the EU. However, policy changes and resource reallocation have opportunity costs (benefits foregone by not using the resources in other ways), and therefore it is necessary to argue convincingly that a health promotion strategy, with dietary guidelines as a central feature, is an appropriate policy.

Ideally, a comprehensive cost benefit analysis would examine all costs and all benefits of the policy options regardless to whom they accrue. From such a social welfare perspective a policy will be judged worthwhile if the benefits can be shown to outweigh the costs. However such studies are difficult for a number of 
reasons, not least of which is the need to express all costs and benefits in common units (money). Not surprisingly no fully comprehensive cost benefit studies of dietary policies have to date been conducted.

Cost effectiveness studies are narrower in scope but more practicable. They attempt to answer questions about technical efficiency: what is the best way of achieving a given objective, as opposed to examining whether or to what extent the objective is worth pursuing. If the objective in question is to save lives via the prevention of CVD, then within a cost effectiveness framework, alternative policy options can be compared in terms of cost per life year gained.

\section{Methods}

The aim is to provide an overview of cost-effectiveness of a range of health promotion and other preventive interventions in the area of CVD. Those involving dietary change, oriented to individuals, small groups or populations (mass interventions) can be compared with nondietary interventions such as smoking cessation, statin therapy and coronary surgery to prevent heart attack. We contacted experts in the field of health economics and health policy, searched Medline and bibliographies of papers on cost-effectiveness of various interventions. Papers published before 1990 were excluded (e.g. Nissinen et $a l.)^{2}$, because we considered them not to reflect current therapeutic practices and economic circumstances. Results are presented as cost per life year gained, at approximately 1994 sterling prices.

\section{Results}

Few comprehensive studies were available. The evidence available for dietary interventions is sparser than that for drug interventions. Even in the surgical domain, no studies of cost-effectiveness of percutaneous transluminal coronary angioplasty (PTCA, mechanical widening of coronary arteries) in angina were of adequate quality to meet the inclusion criteria of a recent review ${ }^{3}$.

The table shows the main results of the studies identified, in descending order of cost effectiveness. Two studies of a variety of interventions are placed at the end of the table. Cost effectiveness estimates are very sensitive to the assumptions made about the duration of risk reduction, as the results for the Oxcheck and Family heart study show ${ }^{4}$.

Cost effectiveness estimates for various dietary interventions are shown. For comparison, estimates are presented based on 'single factor' trials of smoking cessation, multiple risk factor interventions (Oxcheck and the Family heart studies), and drug treatments, most of which are primarily for blood pressure lowering.

It should be borne in mind that the cost effectiveness estimates are dependent on the level of disease risk assumed in the target population. The greater the risk, the more events are potentially preventable. In the study of Ebrahim et $a l^{5}$, the baseline level of risk is moderate (3\% per year). In groups with a higher risk of CVD the costeffectiveness will be greater, and vice versa.

\section{Discussion}

\section{Main findings}

This overview found central estimates of cost per life year gained (CPLYG) for population-wide healthy eating promotion of $£ 14-£ 560$. The range of the costeffectiveness estimates reflects the broad range of assumptions used in their calculation, and the difficulties involved in modelling long-term and multifactorial effects such as dietary change. Nevertheless, the estimates are favourable in comparison with those for smoking interventions (around £500), and superior to all other forms of prevention, including health screening (at least £900) and modern cholesterol-lowering drugs (£8200). An American study produced an estimated CPLYG of £1900, but this modelled the effect of an expensive nationwide campaign and assumed a small resulting reduction in CHD risk ${ }^{6}$.

Care should be taken when making direct comparisons between studies because of differences in location, times, and methods employed. In the latter case, a number of methodological controversies remain unresolved - for example at what rate (including zero) future health gains should be discounted to reflect society's preference for immediate benefits (see for example, Johannesson and Johansson $^{7}$ ). The only adjustment we have made to the costs per life year reported in each study is to convert US\$ to UK£.

\section{The nature of the evidence}

The best evidence for cost effectiveness of a given health promotion intervention would come from randomised controlled trials (RCTs). Measurement of health gains and economic costs and savings, in the medium to long term, say five to 20 years, would provide unambiguous evidence of cost effectiveness, provided the trial was well designed and conducted. Key requirements are that intervention and control groups are randomly allocated, and that the control group is not influenced by the intervention. However, mass modification of dietary behaviour is a difficult subject to study using RCTs of individuals. One way of overcoming this would be to allocate whole communities to receive the intervention and to compare them with unexposed control communities. It can prove difficult in practice to keep the control community isolated from the influences of the intervention. This problem of 'contamination' was encountered in Finland, when the control population in Kuopio improved their risk factor profile by a similar degree to that in North Karelia, where the interventions were 
Table 1 Cost effectiveness estimates (cost per life year gained) of dietary prevention, and other preventive and therapeutic interventions

\begin{tabular}{|c|c|c|c|c|}
\hline Nature of intervention & Study & Participants (age) & Model used for estimating health gain & Cost per life year gained $\left(£ \cup K^{\star}\right)$ \\
\hline $\begin{array}{l}\text { Population-based healthy } \\
\text { eating promotion }\end{array}$ & $\begin{array}{l}\text { Kristiansen, Eggen and } \\
\text { Thelle } 1991^{9}\end{array}$ & $\begin{array}{l}\text { Norwegian population } \\
(40-49)\end{array}$ & $\begin{array}{l}\text { Norwegian cholesterol lowering } \\
\text { programme }\end{array}$ & $£ 14$ \\
\hline $\begin{array}{l}\text { Community based health } \\
\text { promotion }\end{array}$ & Baxter et al. $1997^{10}$ & English adults (18-64) & 'epidemiological model' & $£ 42$ \\
\hline $\begin{array}{l}\text { Mass media led anti-smoking } \\
\text { campaign }\end{array}$ & $\begin{array}{l}\text { Ratcliffe, Cairns and } \\
\text { Platt } 1997^{11}\end{array}$ & Scottish adults & $\begin{array}{l}\text { Prevent model } 6 \% \text { discounted } \\
\text { projection }\end{array}$ & $£ 300-580$ \\
\hline $\begin{array}{l}\text { Nicotine patches prescribed for } 12 \\
\text { weeks by GPs }\end{array}$ & $\begin{array}{l}\text { Stapleton, Lowin and } \\
\text { Russell } 1999^{12}\end{array}$ & English adults & $\begin{array}{l}\text { Efficacy trial and GP resource } \\
\text { use survey } \\
\text { 'Treatment model' }\end{array}$ & $£ 350$ - 790 depending on age \\
\hline $\begin{array}{l}\text { Nurse screening and short advice } \\
\text { sessions }\end{array}$ & Wonderling et al. $1996^{4}$ & English men (35-64) & $\begin{array}{l}\text { Oxcheck study and Dundee risk score. } \\
\text { Discounted projection, 1-20 years. } \\
\text { Gross CPLYG }\end{array}$ & $\begin{array}{l}£ 900-21000 \text { men } \\
£ 1000-42000 \text { women depending } \\
\text { on duration of effect }\end{array}$ \\
\hline
\end{tabular}

sessions

Populationwide programme (£3 per

Tosteson et al. $1997^{6} \quad$ US adults (35-84)

Discounted projection, 1-20 years.

Gross CPLYG

person per year) to reduce cholesterol

$2 \%$ reduction in cholesterol

CHD Policy model

\section{Nurse screening and longer advice \\ Wonderling et al. $1996^{4} \quad$ English families} sessions

Coronary artery bypass graft

Screening and dietary advice

Drugs for mild/moderate hypertension

Various interventions for preventing

CHD
Dougenis, Naik and Brown $1992^{13}$

Kristiansen, Eggen and Thelle $1991^{\circ}$

Edelson et al. $1990^{14}$ (40-49)

US adults (35-64)

$3 \%$ per year baseline

risk
Family heart study and Dundee risk score. Discounted 10 year projection. Gross CPLYG

Retrospective cost analysis in 15 patients $\rightarrow £ 4050$ per patient (1990 prices)

Norwegian cholesterol lowering

programme

CHD policy model

Sheffield life-table $6 \%$ per annum discounted rate. Gross CPLYG

$(95 \% \mathrm{Cl})$.


on duration of effect

£1900

$£ 1100-24000$ men

$£ 3300$ - 145000 women depending

on duration of effect

No cost-effectiveness studies identified

$£ 14600$

Beta adrenergic blocker $£ 6400$ Diuretic $£ 9600$

Calcium channel blocker $£ 19000$ Alpha adrenergic blocker $£ 36000$ ACE inhibitor £42 000

Aspirin $£ 50$ (30-320)

Beta blockers £230 (170-410)

Mediterr. diet $£ 290(200-2000)$

Fish diet £560 (330-2200)

Simvastatin £8200 (6200-11 300)

* US dollars converted at $£ 1=\$ 1.7$.

CPLYG: Cost per life year gained. $95 \% \mathrm{Cl}$ : $95 \%$ confidence interval.

Approximately 1994 prices. 
targeted. Time needed and cost are important hindrances to both individual and community based studies.

The cost effectiveness studies we identified reflect these difficulties. The studies utilise findings from trials or observational studies which provide estimates of life years gained as a result of an intervention. Estimates of the financial costs and savings associated with the intervention are further used to calculate cost effectiveness either on a gross (ignoring savings) or net basis. The modelling techniques are imprecise, but provide broad estimates of the cost effectiveness of the spectrum of policies which might be adopted. Good quality comparative studies are likely to yield the most reliable results because a range of interventions is evaluated using common methodology and assumptions. We found one such study ${ }^{5}$, which concludes that statins have limited cost effectiveness in primary prevention of $\mathrm{CHD}$, and that tobacco control, food policy, promotion of physical activity, and poverty reduction are the key public health measures to be adopted.

\section{Cardiovascular screening or bealtb protection?}

A number of trials of cardiovascular screening and intervention have been carried out, some based in general practices in the $\mathrm{UK}^{4}$. Results of the latter have been used to estimate cost effectiveness, which varies widely depending on the assumed duration of the risk factor and behaviour changes, and the underlying level of coronary risk. The estimated CPLYG is at least $£ 900$, reflecting the generally high cost of health gain based on the medical model, particularly for those not at high disease risk. Population-wide approaches such as media campaigns, on the other hand, are likely to be less costly. However, in terms of assembling evidence it is difficult to attribute changes in dietary or other health behaviours to a particular intervention, given that at any one time several influences are likely to be acting (mass media advertising, technological change and food prices, as well as health messages). There appears to be a contextual effect which promotes dietary change, such as that which occurred during the 1980s when polyunsaturated margarines replaced much of the butter eaten in northern European countries. It is clear from food supply and intake data from many countries that both food habits and nutritional intakes are substantially modifiable. The few relevant studies which we have identified are of poor methodological quality, but do suggest that health protection (public health) approaches can be cost effective in the prevention of CVD.

\section{Implications of the cost-effectiveness findings for food policy in $\mathrm{EU}$ member states}

Health protection policies are likely to be relatively cost effective. There is a need to identify priorities in individual EU member states. Policies to be considered by member states, and for EU support, include: fiscal and legislative measures in agriculture; universal food education; improved institutional food provision such as hospital and school food; regulation of the commercial promotion of salty, high fat and high sugar foods.

Dietary advice as a part of health promotion in primary care for the GENERAL POPULATION appears to be relatively cost ineffective.

The knowledge-attitudes-behaviour model is only modestly effective among healthy people.

Suitable primary care systems do not exist in all member states, but where they do, dietary advice targeted at high-risk groups, with identified illness or elevated risk factor levels, may be cost effective. Such strategies are likely to increase demand for both inexpensive drugs such as thiazide diuretics and expensive drugs such as statins.

A related need is for a harmonised EU nutritional surveillance system to allow comparison of intakes and trends in intakes within and between member states. A recent report $^{8}$, shows that almost all existing member states have a surveillance system. Harmonisation of the diverse national systems is essential for an EU wide strategy. Member states should be supported with funds to achieve the necessary changes.

A recent estimate of direct and indirect costs of cardiovascular disease in the EU is 180 billion Euro* The magnitude of this figure emphasises that resources could be applied to the objective of dietary change, with a net gain to health and the economy in the EU.

\section{References}

1 Brunner EJ, White IR, Thorogood M, Bristow A, Curle D, Marmot MG. Can dietary interventions change diet and cardiovascular risk factors? A meta-analysis of randomized controlled trials. Am. J. Public Health 1997; 87: 1415-22.

2 Nissinen A, Tuomilehto J, Kottke TE, Puska P. Costeffectiveness of the North Karelia Hypertension Program. 1972-1977. Medical Care 1986; 24: 767-80.

3 Sculpher MJ, Petticrew M, Kelland JL, Elliott RA, Holdright DR, Buxton MJ. Resource allocation for chronic stable angina: a systematic review of effectiveness, costs and costeffectiveness of alternative interventions. Health Technol. Assessment 1998; 2(10): i-iv, 1-176.

4 Wonderling D, Langham S, Buxton M, Normand C, McDermott C. What can be concluded from the Oxcheck and British family heart studies: Commentary on cost effectiveness analyses. British Medical Journal 1996; 312: 1274-8.

5 Ebrahim S, Davey Smith G, McCabe C, Payne N, Pickin M, Sheldon TA, et al. What role for statins? A review and economic model. Health Technol. Assessment 1999; 3(19): 191.

6 Tosteson AN, Weinstein MC, Hunink MG, Mittleman MA, Williams LW, Goldman PA, Goldman L. Cost-effectiveness of population-wide educational approaches to reduce cholesterol levels. Circulation 1997; 95: 24-30.

7 Johannesson M, Johansson P. The discounting of lives saved

*Personal communication. M. Rayner, British Heart Foundation Health Promotion Reseaech Group, Department of Public Health, University of Oxford, UK. 
in future generations - some empirical results. Health Economics 1996; 5: 329-32.

8 Schmitt A, Chambolle M, Millstone E, Brunner, EJ, Lobstein T. Nutritional surveillance in Europe. ESTO/IPTS Report C-1O97, 1-73, 1998.

9 Kristiansen IS, Eggen AE, Thelle DS. Cost effectiveness of incremental programmes for lowering serum cholesterol concentration: is individual intervention worth while? British Medical Journal 1991; 302: 1119-22.

10 Baxter T, Milner P, Wilson K, Leaf M, Nicholl J, Freeman J, Cooper N. A cost effective, community based heart health promotion project in England: prospective comparative study. British Medical Journal 1997; 315: 582-5.

11 Ratcliffe J, Cairns J, Platt S. Cost effectiveness of a mass media-led anti-smoking campaign in Scotland. Tobacco Control 1997; 6: 104-10.

12 Stapleton JA, Lowin A, Russell MA. Prescription of transdermal nicotine patches for smoking cessation in general practice: evaluation of cost-effectiveness. Lancet 1999; 354: $210-5$.

13 Dougenis D, Naik S, Brown AH. Is repeated coronary surgery for recurrent angina cost effective? Eur. Heart J. 1992; 13: 914

14 Edelson JT, Weinstein MC, Tosteson AN, Williams L, Lee TH, Goldman L. Long-term cost-effectiveness of various initial monotherapies for mild to moderate hypertension. JAMA 1990; 263: 407-13. 